\title{
Metastatic lymph node ratio and Lauren classification are independent prognostic markers for survival rates of patients with gastric cancer
}

\author{
HUAN WANG ${ }^{1,2 *}$, XIAO-MING XING ${ }^{3 *}$, LEI-NA MA ${ }^{1}$, LIAN LIU $^{4}$, \\ $\mathrm{JING} \mathrm{HAO}^{4}$, LING-XIN FENG ${ }^{1}$ and ZHUANG YU ${ }^{1}$
}

\begin{abstract}
${ }^{1}$ Department of Oncology, The Affiliated Hospital of Qingdao University; ${ }^{2}$ Department of Medical Oncology, Qilu Hospital of Shandong University; ${ }^{3}$ Department of Pathology, The Affiliated Hospital of Qingdao University; Qingdao, Shandong 266000;

${ }^{4}$ Department of Medical Oncology, Qilu Hospital of Shandong University, Jinan, Shandong 250012, P.R. China
\end{abstract}

Received March 17, 2017; Accepted November 2, 2017

DOI: $10.3892 / \mathrm{ol} .2018 .8497$

\begin{abstract}
The long-term prognosis for patients with gastric cancer (GC) following radical resection remains poor. It is important to identify prognostic markers to predict survival. In the present retrospective study, the association between the metastatic lymph node ratio (rN) and the Lauren classification on predicting overall survival (OS) was investigated. Furthermore, a subgroup analysis was performed on the Lauren classification, using $\mathrm{rN}$ score as an independent prognostic marker. In total, 261 pathologically confirmed patients with GC were retrospectively reviewed. Kaplan-Meier curves and Cox's proportional hazards modeling were applied to analyze the OS of patients, and were utilized in the subgroup analysis. Receiver operating characteristic (ROC) curves were used to compare the accuracy of prognosis between the $\mathrm{rN}$ score and lymph node staging ( $\mathrm{N}$ stage). The $\chi^{2}$ test was used to analyze the association between the $\mathrm{rN}$ score and Lauren classification. Univariate survival and multivariate analysis demonstrated that the $\mathrm{rN}$ score and Lauren classification were significant prognostic markers for patients with GC. The ROC analysis confirmed that the $\mathrm{rN}$ score was more effective than $\mathrm{N}$ staging for OS prediction. Subgroup analysis indicated that $\mathrm{rN}$ was more accurate at predicting OS time in patients with diffuse type GC. The rN score and the Lauren classification were independent prognostic factors for the OS of patients with GC following radical resection, and the $\mathrm{rN}$ score was more accurate than the $\mathrm{N}$ stage for predicting the prognosis. Overall, the $\mathrm{rN}$ may be suitable as an independent predictor for OS in patients with diffuse type GC.
\end{abstract}

Correspondence to: Professor Zhuang Yu, Department of Oncology, The Affiliated Hospital of Qingdao University, 16 Jiangso Road, Shinan, Qingdao, Shandong 266000, P.R. China

E-mail: yuzhuang2002@163.com

*Contributed equally

Key words: gastric cancer, metastatic lymph node ratio, lymph node staging, Lauren classification, prognosis

\section{Introduction}

Gastric cancer (GC) is the fourth most common type of cancer, and the second leading cause of cancer-associated mortality worldwide (1). GC mortality rates continue to increase yearly, particularly in low- and middle-income countries (2). The long-term prognosis remains poor due to postoperative recurrence and metastasis; and therefore, it is important to identify new prognostic markers for the identification of higher risk patients, and to direct the application of adjuvant chemotherapy regimens.

Several factors have been previously associated with the prognosis of patients with GC including tumor diameter, histological differentiation, lymph node status and surgical margin status. However, it has been demonstrated that the number of metastatic lymph nodes may be one of the most reliable prognostic markers available (3). At present, the 7th edition of the Tumor-Node-Metastasis (TNM) staging system by the American Joint Committee on Cancer (AJCC) (4) is commonly used to determine the stage of GC and its prognosis. $\mathrm{N}$ stage is determined by the number of metastatic lymph nodes. According to this classification, it is necessary to examine sufficient lymph nodes, with $\geq 15$ required for the accurate diagnosis of the $\mathrm{N}$ stage in GC (4). However, an insufficient number of lymph nodes commonly hampers the clinical application of lymph node staging in GC specimens $(5,6)$. Previously, the lymph node ratio $(\mathrm{rN})$, defined as the ratio of metastatic lymph nodes to the total lymph nodes examined, has been demonstrated as a valuable prognostic factor for the overall survival (OS) of resectable GC (7-10). $\mathrm{rN}$ has been demonstrated as more reliable and accurate than $\mathrm{N}$ stage in predicting survival outcomes (11-13); however, another study has contradicted these studies (14). Further investigation is therefore required in order to resolve this conflict.

The Lauren classification sub-classifies GC into diffuse, intestinal and mixed type, with each type demonstrating distinct clinical and pathological characteristics $(15,16)$. It has been demonstrated that diffuse type gastric carcinomas are associated with a worse prognosis than intestinal type gastric carcinoma, and that the Lauren classification type exhibits 
independent prognostic significance (17). However, to the best of our knowledge, there has been no study analyzing the association between Lauren classification and $\mathrm{rN}$ on predicting the OS time for patients with GC.

The aims of the present study were to: i) Evaluate the prognostic value of the $\mathrm{rN}$ and Lauren classification in patients with GC; ii) compare the accuracy of prognosis between the $\mathrm{rN}$ and $\mathrm{N}$ stages in patients with $\mathrm{GC}$; iii) investigate the prognostic relevance of the $\mathrm{rN}$ in each Lauren classification subtype.

\section{Materials and methods}

Eligible patients. For this retrospective study, the medical records for 332 patients who underwent curative GC resection between May 2007 and May 2011 at the Affiliated Hospital of Qing Dao University were reviewed and analyzed.

The inclusion criteria included: i) Pathologically confirmed adenocarcinoma; ii) the absence of distant metastasis at the time of primary diagnosis; iii) complete preoperative staging data was available; iv) the patient received radical tumor resection (R0) with D1 or D2 lymph adenectomy; v) complete postoperative pathological data was available.

The exclusion criteria included: i) Patients presented with multiple primary cancers; ii) patients received preoperative treatment; iii) patients had peritoneal dissemination during surgery; iv) patient mortality was caused by factors other than GC.

In total, 261 eligible patients were included in the present study (Fig. 1). Pathological lymph node status and Lauren classification were evaluated by pathologists, and the $\mathrm{rN}$ was calculated for each patient.

Clinical and pathological data collection and variable classification. Information on clinical and pathological variables were obtained from medical records and pathological reports, which included age, sex, smoking status, drinking status, tumor diameter, differentiation, pathological type, venous invasion, Lauren classification, node status, the number of lymph nodes examined, number of metastatic lymph nodes, $\mathrm{T}$ stage, $\mathrm{N}$ stage and the TNM stage evaluated according to the 7th edition of AJCC TNM staging system (18). Classification thresholds for tumor diameter $(\leq 4,4-6,6-8,>8 \mathrm{~cm})$ were defined by comparing survival rates between different sized groups using $1 \mathrm{~cm}$ as the standard interval, and the prognostic accuracy of all tumor diameter categories were evaluated based on the Harrell concordance index (19-24). The independent Ethics Committee of The Affiliated Hospital of Qingdao University (Shandong, China) approved the study.

According to the number of lymph nodes examined, patients were divided into two groups, $\geq 15$ and $<15$ lymph nodes examined. $\mathrm{rN}$ was defined as the number of metastatic lymph nodes divided by the total number of lymph nodes examined. According to previous studies, $\mathrm{rNs}$ were divided into four score categories: i) rN0 (no lymph nodes involved); ii) $\mathrm{rN} 1$ (ratio $>0$ and $\leq 0.2$ ); iii) $\mathrm{rN} 2$ (ratio $>0.2$ and $\leq 0.5$ ); iv) rN3 (ratio $>0.5)(25,26)$.

Follow-up. During the first 2 years after radical resection, patients were followed up via telephone contact at 3-month intervals. Between 2 and 5 years, follow-up was performed at 6-month intervals. After 5 years, patients were followed
Table I. The characteristics of 261 patients with gastric cancer.

\begin{tabular}{lrc}
\hline Variable & $\mathrm{n}$ & $\%$ \\
\hline Sex & & \\
Male & 188 & 72.03 \\
Female & 73 & 27.97 \\
Age, years & & \\
$<60$ & 181 & 69.35 \\
$\geq 60$ & 80 & 30.65
\end{tabular}

Tumor pathological differentiation

Well

Moderate

Poorly

Unknown

81.61

Pathologic type

Adenocarcinoma

Ring cell carcinoma

93.87

Tumor-node-metastasis stage

I

245

6.13

9.58

II

45.21

III

Lymph nodes examined, $\mathrm{n}$

$\begin{array}{lll}\geq 15 & 155 & 59.39 \\ <15 & 106 & 40.61\end{array}$

Lymph node stage

0

1

2

61

23.37

26.82

24.9

3

24.9

Metastatic lymph node ratio score 0

23.37

1

31.03

2

27.20

3

18.39

Lauren classification

Intestinal type $\quad 67$

25.67

Diffuse type

29.5

Mixed type

44.83

Status

Surviving

103

39.46

Deceased

158

60.54

TNM, tumor-node-metastasis.

up once a year. In total, 16 patients lost to follow-up within the first year after surgery. In total, the follow-up period was between August 2007 and May 2016. The endpoint was the OS time, which was the time between the date of surgery and the date of final follow-up or patient mortality.

Statistical analysis. Patient characteristics were evaluated using a Student's t-test for continuous data and a $\chi^{2}$ test for categorical variables. Univariate analysis of survival was 


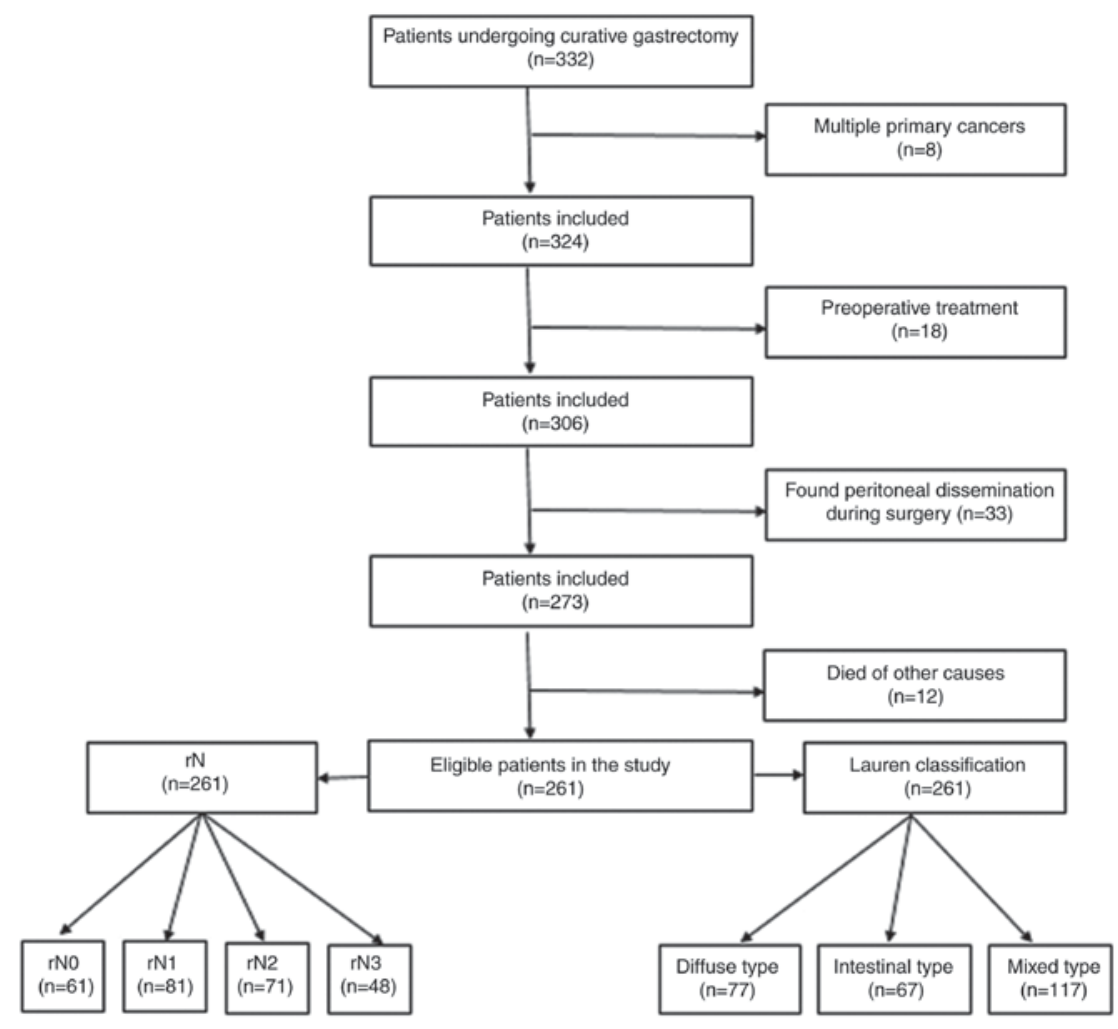

Figure 1. Flowchart of eligible patients enrolled in this study. rN, lymph node ratio.

performed using Kaplan-Meier estimator curves. The differences between groups were compared using the Log-rank $\chi^{2}$ test. Multivariate analysis was performed using Cox proportional hazards modeling to identify independent predictors, which only included the variables with statistical significance $(\mathrm{P}<0.05)$ obtained from univariate analysis. Hazard ratios (HR) and $95 \%$ confidence intervals (CI) were calculated in order to compare the relative risk associated with various factors. Receiver operating characteristic (ROC) curves were used to evaluate which variable demonstrated a higher prognostic value. Kaplan-Meier estimator curves for OS and Cox proportional hazard regression models were used to analyze the prognosis associated with the rN score in Lauren classification subgroups. The $\chi^{2}$ test was applied to evaluate the association between the $\mathrm{rN}$ score and the Lauren classification. All statistical analysis was performed using SPSS (version 22.0; IBM Corp., Armonk, NY, USA). $\mathrm{P}<0.05$ was considered to indicate a statistically significant difference.

\section{Results}

Patient characteristics. Patient characteristics are summarized in Table I. In total, 188 (72.03\%) male and $73(27.97 \%)$ female patients with a mean age of 54 years, primarily presenting with stage II and III disease $(n=118,45.21 \%)$, were enrolled in to the present study. Histopathological examination revealed that the majority of patients $(n=213,81.61 \%)$ were diagnosed with poorly differentiated adenocarcinoma, and 106 patients $(40.61 \%)$ had $<15$ examined lymph nodes The N-stage distribution was even among the 4 groups, whereas $\mathrm{rN} 3(\mathrm{n}=48,18.39 \%)$ was the least common category.
Mixed type carcinoma $(n=117,44.83 \%)$ was the most common Lauren classification. In total, 103 patients (40.61\%) survived and 158 patients $(60.54 \%)$ had succumbed to GC by the end of the study. Overall, the median survival time was 30 months (range, 3-63 months).

Analysis of prognostic factors in the whole patient cohort. As presented in Table II, the univariate survival analysis with Kaplan-Meier curves demonstrated that the significant prognostic factors for OS included tumor diameter $(\mathrm{P}<0.001)$, node status $(\mathrm{P}=0.004), \mathrm{rN}$ score $(\mathrm{P}=0.001)$, Lauren classification $(\mathrm{P}<0.001), \mathrm{N}$ stage $(\mathrm{P}=0.001)$ and $\mathrm{TNM}$ stage $(\mathrm{P}<0.001)$, whereas sex $(\mathrm{P}=0.486)$, age $(\mathrm{P}=0.169)$, $\mathrm{T}$ stage $(\mathrm{P}=0.104)$, pathological differentiation $(\mathrm{P}=0.43)$, the number of lymph nodes examined $(\mathrm{P}=0.813)$, vessel cancer embolus $(\mathrm{P}=0.675)$, smoking status $(\mathrm{P}=0.843)$, drinking status $(\mathrm{P}=0.85)$ and pathological type $(\mathrm{P}=0.189)$ were not significantly associated with OS (Fig. 2).

As presented in Table III, multivariate analysis with Cox regression model further identified the independent prognostic factors for OS, including tumor diameter $(\mathrm{P}=0.03)$, $\mathrm{rN}$ score $(\mathrm{P}<0.001)$ and Lauren classification $(\mathrm{P}<0.001)$. Multivariate analysis also indicated that patients with an increased $\mathrm{rN}$ were associated with the shortest OS time, and the diffuse type of Lauren classification was also associated with a poorer prognosis. In the analysis of $\mathrm{rN}$ score, using $\mathrm{rN} 3$ as the reference group, the HRs for $\mathrm{rN} 0, \mathrm{rN} 1$, and $\mathrm{rN} 2$ were $0.16(95 \% \mathrm{CI}$, 0.14-0.19), 0.22 (95\% CI, 0.2-0.25) and 0.3 (95\% CI, 0.28-0.31), respectively. In Lauren classification analysis, using mixed type as the reference group (HR: 1), the HRs for intestinal and diffuse type were 0.56 (95\% CI, 0.32-0.97) and 1.9 (95\% CI, 1.26-2.86), respectively. 
Table II. Univariate analysis of the potential predictive factors for overall survival time.

\begin{tabular}{|c|c|c|c|c|c|}
\hline Variable & Median & Standard error & $95 \%$ confidence interval & $\chi^{2}$ & P-value \\
\hline \multicolumn{6}{|l|}{ Sex } \\
\hline Male & 74.73 & 3.01 & $68.83-80.63$ & \multirow[t]{2}{*}{0.485} & \multirow[t]{2}{*}{0.486} \\
\hline Female & 70.36 & 5.27 & $60.03-80.69$ & & \\
\hline \multicolumn{6}{|l|}{ Age, years } \\
\hline$<60$ & 76.14 & 3.11 & $70.03-82.24$ & \multirow[t]{2}{*}{1.891} & \multirow[t]{2}{*}{0.169} \\
\hline$\geq 60$ & 67.59 & 4.85 & 58.09-77.09 & & \\
\hline \multicolumn{6}{|l|}{ Tumor diameter, $\mathrm{cm}$} \\
\hline$\leq 4$ & 86.31 & 3.93 & 78.6-94.01 & \multirow[t]{4}{*}{19.276} & \multirow[t]{4}{*}{$<0.001$} \\
\hline $4-6$ & 72.44 & 4.41 & $63.8-81.07$ & & \\
\hline $6-8$ & 53.03 & 6.22 & $40.83-65.23$ & & \\
\hline$>8$ & 65.07 & 7.71 & $49.96-80.17$ & & \\
\hline \multicolumn{6}{|l|}{ T stage } \\
\hline 1 & 93.33 & 10.06 & $73.62-113.04$ & \multirow[t]{4}{*}{6.166} & \multirow[t]{4}{*}{0.104} \\
\hline 2 & 85.38 & 6.29 & $73.06-97.7$ & & \\
\hline 3 & 74.71 & 3.59 & $67.67-81.76$ & & \\
\hline 4 & 48.92 & 4.06 & $40.96-56.88$ & & \\
\hline \multicolumn{6}{|l|}{ Differentiation } \\
\hline Well & 39.75 & 10.14 & $19.88-59.62$ & \multirow[t]{4}{*}{2.759} & \multirow[t]{4}{*}{0.430} \\
\hline Moderate & 72.58 & 6.42 & $59.99-85.18$ & & \\
\hline Poor & 75 & 3.03 & $69.07-80.94$ & & \\
\hline Unknown & 52 & 0 & $52.00-52.00$ & & \\
\hline \multicolumn{6}{|l|}{ Pathological type } \\
\hline Adenocarcinoma & 75.97 & 2.77 & $70.54-81.41$ & \multirow[t]{2}{*}{1.728} & \multirow[t]{2}{*}{0.189} \\
\hline Ring cell carcinoma & 55.85 & 11.3 & $33.71-77.99$ & & \\
\hline \multicolumn{6}{|l|}{ Node status } \\
\hline Negative & 88.33 & 4.32 & $79.86-96.81$ & \multirow[t]{2}{*}{8.398} & \multirow[t]{2}{*}{0.004} \\
\hline Positive & 69.27 & 3.11 & $63.18-75.36$ & & \\
\hline \multicolumn{6}{|c|}{ Lymph nodes examined, $\mathrm{n}$} \\
\hline$\geq 15$ & 73.72 & 3.35 & $67.14-80.29$ & 0.056 & 0.813 \\
\hline$<15$ & 73.03 & 4.2 & $64.79-81.27$ & & \\
\hline $\mathrm{N}$ stage & & & & & \\
\hline 0 & 88.33 & 4.32 & $79.86-96.81$ & 15.804 & 0.001 \\
\hline 1 & 74.7 & 5 & $64.9-84.5$ & & \\
\hline 2 & 73.77 & 5.17 & $63.63-83.9$ & & \\
\hline 3 & 57.9 & 5.5 & $47.12-68.69$ & & \\
\hline $\begin{array}{l}\text { Metastatic lymph nod } \\
\text { ratio score }\end{array}$ & & & & & \\
\hline 0 & 87.52 & 2.72 & $82.19-92.85$ & 19.407 & 0.001 \\
\hline 1 & 76.28 & 2.57 & $71.24-81.32$ & & \\
\hline 2 & 65.91 & 2.56 & $60.89-70.93$ & & \\
\hline 3 & 54.29 & 3.08 & $48.25-60.33$ & & \\
\hline TNM stage & & & & & \\
\hline I & 88.13 & 6.91 & 74.6-101.66 & 20.616 & $<0.001$ \\
\hline II & 83.95 & 3.51 & $77.07-90.82$ & & \\
\hline III & 59.61 & 4.16 & $51.46-67.75$ & & \\
\hline Lauren classification & & & & & \\
\hline Intestinal type & 89.07 & 2.79 & $83.60-94.54$ & 23.746 & $<0.001$ \\
\hline Diffuse type & 54.65 & 4.97 & $44.91-64.39$ & & \\
\hline Mixed type & 74.85 & 3.65 & $67.70-82.00$ & & \\
\hline
\end{tabular}


Table II. Continued.

\begin{tabular}{|c|c|c|c|c|c|}
\hline Variable & Median & Standard error & $95 \%$ confidence interval & $\chi^{2}$ & P-value \\
\hline \multicolumn{6}{|c|}{ Vessel cancer embolus } \\
\hline Negative & 74.1 & 2.69 & $68.83-79.37$ & 0.176 & 0.675 \\
\hline Positive & 58.78 & 12.85 & $33.6-83.96$ & & \\
\hline \multicolumn{6}{|c|}{ Smoking status } \\
\hline No & 73.98 & 3.34 & $67.43-80.53$ & 0.039 & 0.843 \\
\hline Yes & 72.34 & 4.26 & $63.98-80.69$ & & \\
\hline \multicolumn{6}{|c|}{ Drinking status } \\
\hline No & 73.33 & 3.31 & $66.83-79.82$ & 0.036 & 0.85 \\
\hline Yes & 73.68 & 4.32 & $65.21-82.15$ & & \\
\hline
\end{tabular}

TNM, tumor-node-metastasis; N stage, lymph node staging; T stage, tumor stage.

A

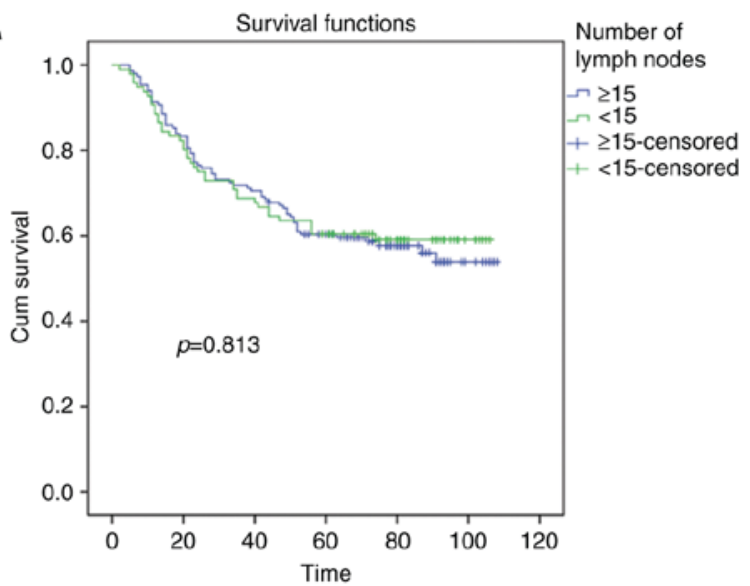

B

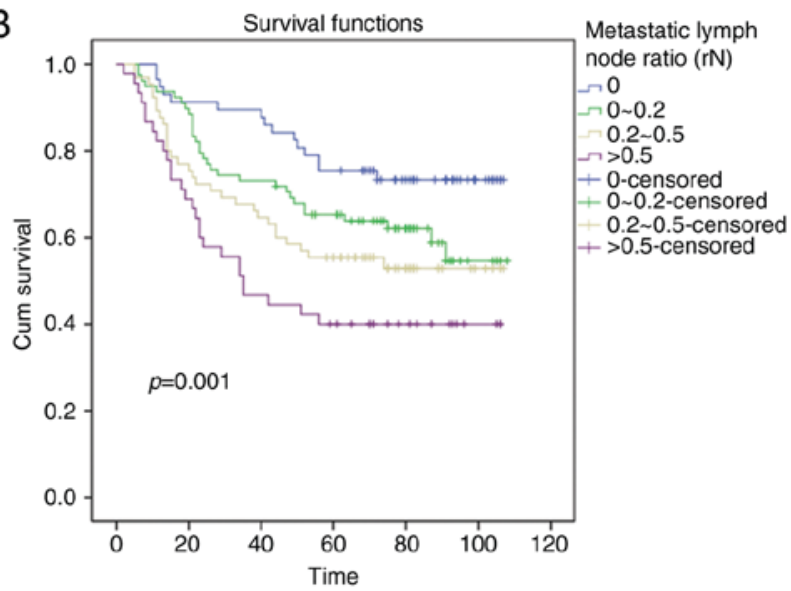

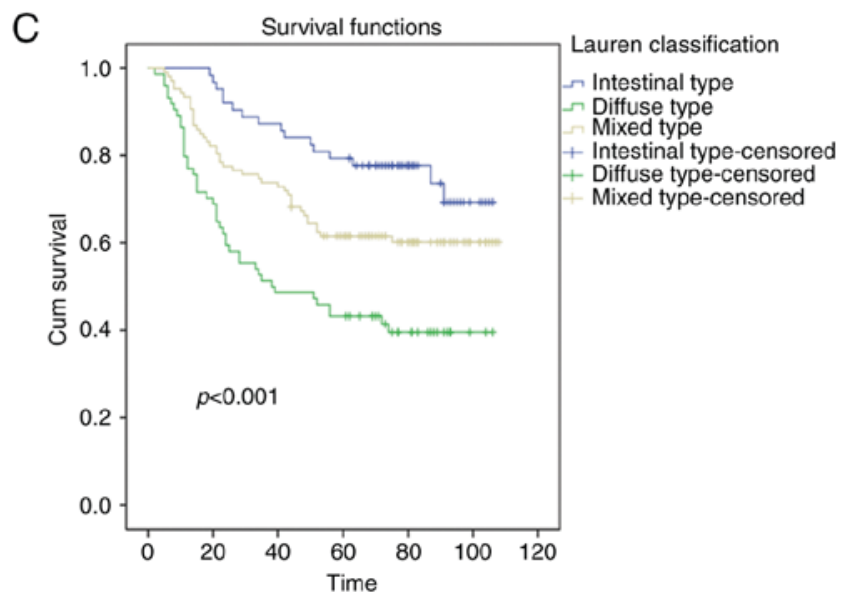

Figure 2. Kaplan Meier curve of overall survival. (A) Overall survival curves of patients according to the number of lymph nodes examined. (B) Overall survival curves of patients according to $(\mathrm{C})$ Overall survival curves of patients according to Lauren classification. rN, lymph node ratio.

As demonstrated in ROC curves from multivariate analysis, the area under the curve for $\mathrm{rN}$ and $\mathrm{N}$ stage was 0.765 (95\% CI, 0.704-0.827) and 0.614 (95\% CI, 0.544-0.683), respectively, a statistically significant difference $(\mathrm{P}=0.002)$. The $\mathrm{rN}$ score had a greater prognostic value for OS compared with $\mathrm{N}$ stage (Fig. 3). In the ROC curve analysis, $\mathrm{N}$ stage and the $\mathrm{rN}$ score were used as test variables, and the survival status of patients was used as the outcome variable; these variables were incorporated into a model and a correction curve was generated.

Subgroup analysis for OS. Kaplan-Meier estimator curves were used to analyze whether the number of lymph nodes examined $(\geq 15$ or $<15)$ had an effect on the prognostic value of $\mathrm{rN}$. An association analysis was performed separately for the two groups and demonstrated that $\mathrm{rN}$ was significantly 
Table III. Multivariable Cox regression analysis to identify independent predictors of overall survival time.

\begin{tabular}{|c|c|c|c|}
\hline Variable & HR & $\begin{array}{l}\% \text { confidence } \\
95 \text { interval }\end{array}$ & P-value \\
\hline Tumor diameter & & & 0.030 \\
\hline 1 & 0.72 & $0.27-1.95$ & 0.520 \\
\hline 2 & 0.78 & $0.34-1.81$ & 0.560 \\
\hline 3 & 2.44 & $1.24-4.93$ & 0.023 \\
\hline 4 & 1 & & \\
\hline Lymph node metastasis & 1.42 & $0.45-4.49$ & 0.550 \\
\hline rN score & & & $<0.001$ \\
\hline 0 & 0.16 & $0.14-0.19$ & $<0.001$ \\
\hline 1 & 0.22 & $0.20-0.25$ & $<0.001$ \\
\hline 2 & 0.3 & $0.28-0.31$ & $<0.001$ \\
\hline 3 & 1 & & \\
\hline Lauren classification & & & $<0.001$ \\
\hline Intestinal type & 0.56 & $0.32-0.97$ & 0.043 \\
\hline Diffuse type & 1.9 & $1.26-2.86$ & 0.003 \\
\hline Mixed type & 1 & & \\
\hline $\mathrm{N}$ stage & & & 0.270 \\
\hline No & 2.36 & $0.57-9.88$ & 0.310 \\
\hline N1 & 1.9 & $0.83-4.32$ & 0.250 \\
\hline $\mathrm{N} 2$ & 0.67 & $0.32-1.40$ & 0.290 \\
\hline $\mathrm{N} 3$ & 1 & & \\
\hline TNM stage & & & 0.390 \\
\hline I & 0.34 & $0.06-1.87$ & 0.210 \\
\hline II & 0.61 & $0.25-1.49$ & 0.280 \\
\hline III & 1 & & \\
\hline
\end{tabular}

$\mathrm{N}$ stage, lymph node stage; rN, metastatic lymph node ratio; TNM, tumor-node-metastasis.

Table IV. Survival rates stratified by $\mathrm{rN}$ score.

Survival rate, $\%$

\begin{tabular}{lccc}
\cline { 2 - 4 } rN score & 1-year & 3-year & 5-year \\
\hline 0 & 91.23 & 84.21 & 75.44 \\
1 & 79.49 & 70.49 & 63.71 \\
2 & 72.31 & 58.46 & 55.34 \\
3 & 60.00 & 44.44 & 39.89 \\
\hline
\end{tabular}

$\mathrm{rN}$, metastatic lymph node ratio.

associated with $\mathrm{OS}$ in both groups $(\mathrm{P}=0.003$ and $\mathrm{P}=0.017$, respectively). The results confirmed that the $\mathrm{rN}$ score was an independent prognostic factor for survival rate, independent of the number of lymph nodes examined (Fig. 4). The survival rates associated with different $\mathrm{rN}$ scores were calculated at 1 , 3 and 5 years. The results demonstrated that increased $\mathrm{rN}$ was associated with shorter OS (Table IV).

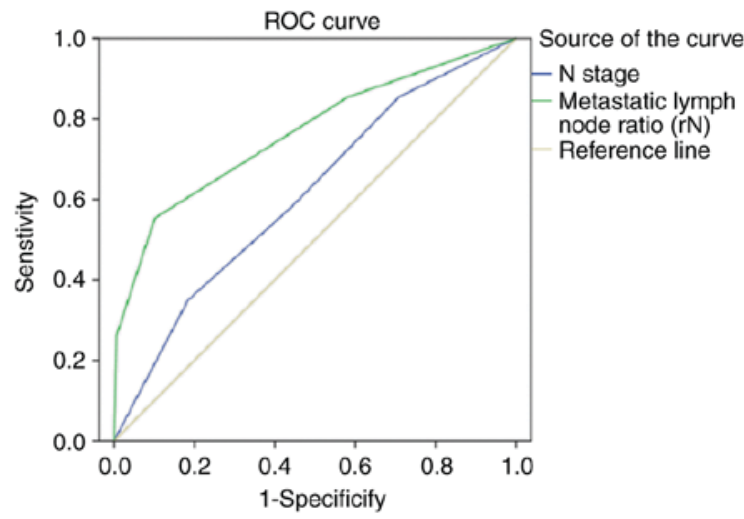

Figure 3. Receiver operating characteristic curve to compare the accuracy of prognosis between $\mathrm{rN}$ and $\mathrm{N}$ stage by the area under the curve on overall survival of patients underwent curative surgery for gastric cancer. rN, lymph node ratio.
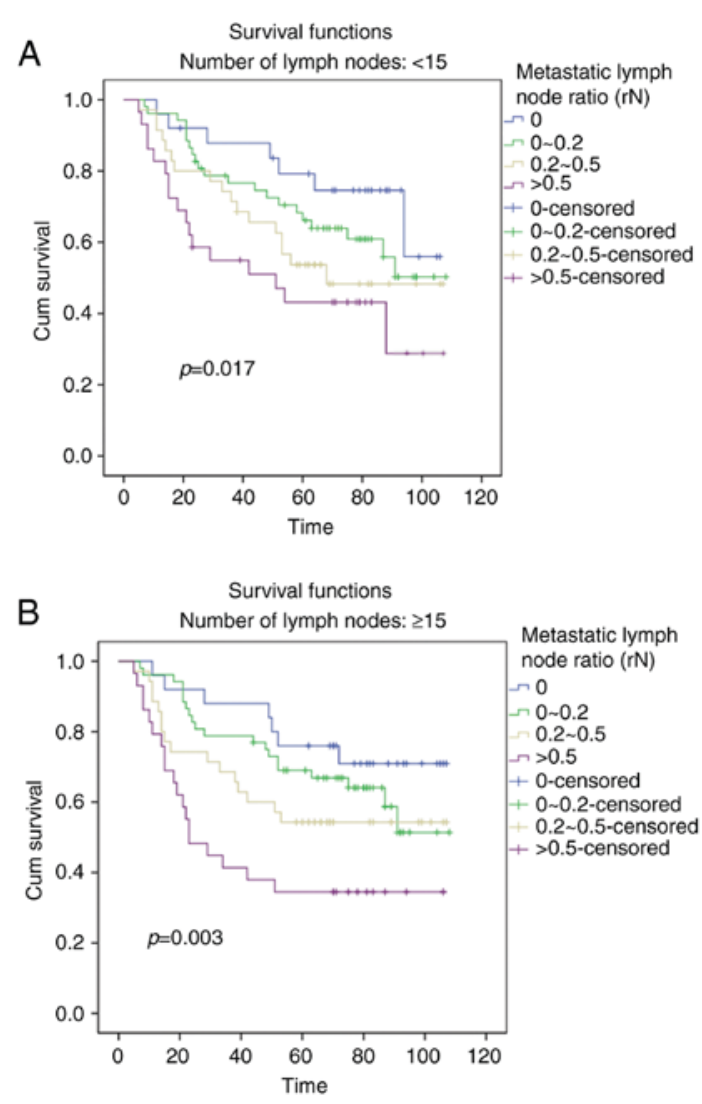

Figure 4. Kaplan-Meier survival curves of rN. (A) Overall survival curves of $\mathrm{rN}$ in a group of the number of lymph nodes examined fewer than 15 (B) Overall survival curves of $\mathrm{rN}$ in the other group of the number of lymph nodes examined more than 15 . rN, lymph node ratio.

The association between $\mathrm{rN}$ scores and the Lauren classification for OS was evaluated using subgroup analyses. Kaplan-Meier curves and Cox's proportional hazard regression models were used to analyze the prognostic relevance of the $\mathrm{rN}$ score categories in each Lauren classification (diffuse, intestinal and mixed type). A significant association with survival was only observed in the diffuse type subgroup ( $\mathrm{P}=0.01$; Fig. 5 and Table V). The $\chi^{2}$ test was applied to evaluate the association between the $\mathrm{rN}$ score and the diffuse type subgroup. No 

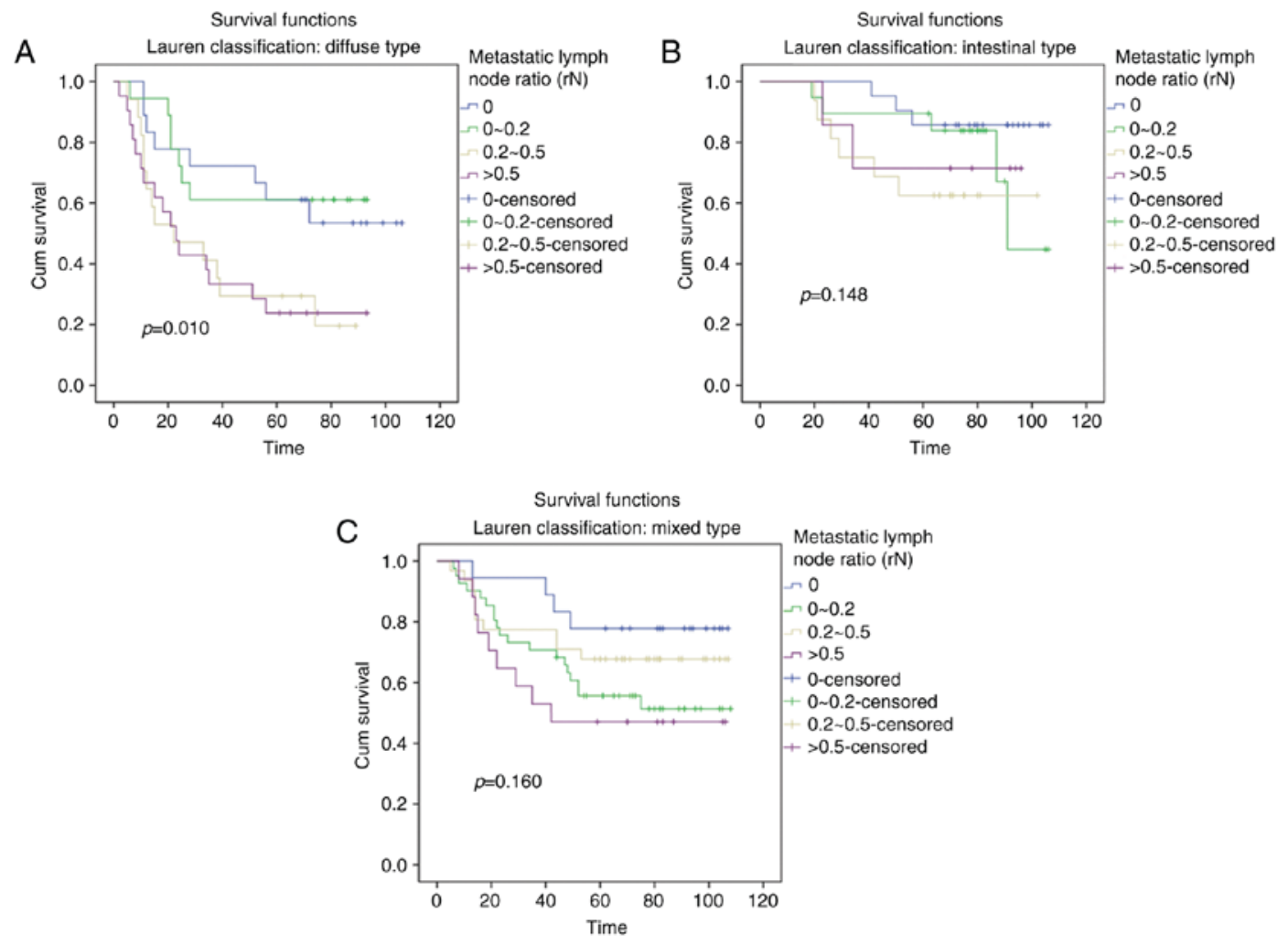

Figure 5. Kaplan-Meier survival curve analysis of the prognostic relevance of $\mathrm{rN}$ categories in each Lauren classification. (A) Overall survival of $\mathrm{rN}$ in the diffuse-type. (B) Overall survival of $\mathrm{rN}$ in intestinal-type. (C) Overall survival of $\mathrm{rN}$ in mixed-type. $\mathrm{rN}$, lymph node ratio.

association was identified between the two factors $(\mathrm{P}=0.223$; Table VI), implying that the $\mathrm{rN}$ score may be used as an independent prognostic factor for OS in the diffuse type subgroup. Cox regression model analysis in the diffuse type subgroup further confirmed this (Table VII). In the diffuse type subgroup, univariate analysis with Kaplan-Meier estimator curves were used to select significant factors, including the $\mathrm{rN}$ score $(\mathrm{P}=0.01)$, $\mathrm{N}$ stage $(\mathrm{P}=0.032)$ and $\mathrm{TNM}$ stage $(\mathrm{P}=0.004)$. Multivariate analysis with Cox regression model demonstrated that the $\mathrm{rN}$ score was an independent predictor for OS time $(\mathrm{P}<0.001)$.

\section{Discussion}

The present study demonstrated that the score and Lauren classification had independent prognostic relevance on predicting the survival of postoperative patients with GC. Overall, the rN score demonstrated a better prognostic value compared with the $\mathrm{N}$ stage, and an increased $\mathrm{rN}$ score was associated with a shorter OS time.

The $\mathrm{N}$ stage is based on the number of local lymph nodes exhibiting metastasis, and has been used in routine clinical practice for years, as it possesses significant diagnostic value for patients with GC. However, it has been demonstrated that an insufficient or extended number of lymph nodes being examined may cause staging deviation (4), which is observed in $~ 15 \%$ of patients with GC when using the TNM staging system (27). rN therefore is associated with potential advantages in minimizing the stage migration phenomenon for patients with an insufficient number of assessed lymph nodes. Using $\mathrm{rN}$ alongside the TNM system may assist in predicting the relapse and survival rates for patients with GC. However, another study could not confirm this result and reported no benefit of $\mathrm{rN}$ over $\mathrm{N}$ stage in the prediction of patient outcome (28). In the present study, ROC curves were used to compare the prediction accuracy between $\mathrm{rN}$ and $\mathrm{N}$ stage. The results demonstrated that $\mathrm{rN}$ was a better metric than $\mathrm{N}$ stage for predicting the patient outcome. However, as the sample size was small, future investigations with a larger cohort are required in order to validate these results.

According to the current TNM staging system, it is necessary to examine $\geq 15$ lymph nodes. However, this is often not achievable in practice due to a surgeon's lack of experience and the low extent of surgical lymph node dissection. This may lead to stage underestimation and affect the management and/or prognosis of a patient. Previous studies have suggested that $\mathrm{rN}$ may still accurately predict patient prognosis, despite requiring an examination of $<15$ lymph nodes $(10,26)$. The present study is in accord with these results. In Western countries, extended lymph node dissection is not considered to provide survival benefit for patients; D1 radical resection is frequently performed, leading to $<15$ lymph nodes being examined $(29,30)$. The results from the present study suggested that the number of examined lymph nodes did not exhibit significant prognostic value for OS.

A number of studies have focused on the prognostic significance of $\mathrm{rN}$ in other types of malignant tumor, including esophageal carcinoma (31), breast cancer (32), non-small cell lung cancer (33), colon cancer (34), pancreatic adenocarcinoma (35) and carcinoid tumors (36). The $\mathrm{rN}$ was identified to be an independent prognostic marker in these types of tumor, with the exception of carcinoid tumors (36). Consistent with these results, the present study demonstrated that the $\mathrm{rN}$ score was a significant prognostic factor based on univariate and 
Table V. Cox's proportional hazard regression models to analyze the prognosis associated with $\mathrm{rN}$ score for each Lauren classification type.

\begin{tabular}{lccccr}
\hline Lauren classification & rN score & Median & Hazard ratio & 95\% confidence interval & P-value \\
\hline Intestinal type & 0 & 92.89 & 0.81 & $0.640-1.025$ & 0.080 \\
& 1 & 86.34 & 0.85 & $0.713-1.014$ & 0.070 \\
& 2 & 78.61 & 0.87 & $0.715-1.058$ & 0.164 \\
Diffuse type & 3 & 70.88 & 1 & - & - \\
& 0 & 72.06 & 0.67 & $0.573-0.784$ & $<0.001$ \\
& 1 & 70.38 & 0.71 & $0.595-0.847$ & $<0.001$ \\
Mixed type & 2 & 40.62 & 0.97 & $0.862-1.091$ & - \\
& 3 & 36.41 & 1 & - & 0.665 \\
& 0 & 87.42 & 0.84 & $0.778-1.064$ & 0.238 \\
& 1 & 76.43 & 0.91 & $0.811-1.067$ & 0.299 \\
& 2 & 67.08 & 0.93 & - & -
\end{tabular}

HR, hazard ratio; CI, confidence interval; rN, metastatic lymph node ratio.

Table VI. $\chi^{2}$ test analysis of the association between $\mathrm{rN}$ score and Lauren classification.

\begin{tabular}{|c|c|c|c|c|c|c|}
\hline \multirow{2}{*}{$\begin{array}{l}\text { Lauren } \\
\text { classification }\end{array}$} & \multicolumn{4}{|c|}{ rN score } & \multirow[b]{2}{*}{$\chi^{2}$} & \multirow[b]{2}{*}{ P-value } \\
\hline & 0 & 1 & 2 & 3 & & \\
\hline Intestinal type & 21 & 19 & 18 & 8 & 8.217 & 0.223 \\
\hline Diffuse type & 19 & 19 & 17 & 22 & & \\
\hline Mixed type & 21 & 43 & 35 & 18 & & \\
\hline
\end{tabular}

$\mathrm{rN}$, metastatic lymph node ratio.

multivariate analyses, as an increased $\mathrm{rN}$ score was associated with a reduced OS time.

Lauren classification is the most commonly used histological system for GC, dating back to 1965. Each classification type has distinct pathological, epidemiological and prognostic characteristics. Previous studies have reported the relevance of the Lauren classification, especially the diffuse and intestinal type, in regards to survival prediction $(16,17,37)$. Qiu et al (38) demonstrated that Lauren classification was an independent prognostic factor, as the patients with diffuse type GC had a worse prognosis compared with the patients with intestinal type GC (38). However, Berlth et al (39) indicated that the Lauren classification was not associated with patient OS. The study did not identify that the diffuse type was independently associated with a poor prognosis, and the Lauren classification was only associated significantly with prognosis in univariate analysis and not in multivariate analysis (39). In the present study, Lauren classification was identified as an independent prognostic factor for OS in univariate and multivariate analysis. The diffuse type classification was associated with the worst prognosis, consistent with the results presented by Qiu et al (38). The present study also conducted subgroup
Table VII. Cox regression analysis to identify independent prognostic predictors of survival in the diffuse type subgroup.

\begin{tabular}{lccr}
\hline Variable & $\begin{array}{c}\text { Hazard } \\
\text { ratio }\end{array}$ & $\begin{array}{c}95 \% \text { confidence } \\
\text { interval }\end{array}$ & P-value \\
\hline $\begin{array}{l}\text { Lymph node } \\
\text { stage }\end{array}$ & & & 0.163 \\
1 & 0.90 & $0.77-1.05$ & 0.187 \\
2 & 1.21 & $0.92-1.59$ & 0.173 \\
3 & 0.77 & $0.59-1.01$ & 0.054 \\
4 & 1 & & \\
Tumor-node- & & & 0.281 \\
metastasis stage & & & 0.100 \\
I & 0.78 & $0.58-1.04$ & 0.191 \\
II & 0.70 & $0.41-1.18$ & \\
III & 1 & & $<0.001$ \\
Metastatic lymph & & & $<0.001$ \\
node ratio score & & & \\
0 & 0.58 & $0.49-0.70$ & \\
1 & 0.63 & $0.48-0.81$ & \\
2 & 0.95 & $0.85-1.07$ & \\
3 & 1 & & \\
\hline
\end{tabular}

analysis based on the Lauren classification. The association of the $\mathrm{rN}$ score with the prognosis in each subgroup was assessed. The $\mathrm{rN}$ score was identified as an independent predictor of survival in the diffuse type subgroup. The $\chi^{2}$ test was applied to assess whether the rN score and the Lauren classification influenced one another; it was demonstrated that there was no association between the $\mathrm{rN}$ score and the diffuse type subgroup. Therefore, rN may be suitable as an independent prognostic marker for patients with diffuse type GC. Cox 
regression modal analysis of the diffuse type subgroup further supported this conclusion. To the best of our knowledge, this is the first report to demonstrate that $\mathrm{rN}$ exhibited particular prognostic significance for patients with diffuse type GC.

The results of the present study should be considered in the context of its limitations. The sample size of the present study was not large enough for analysis by further subgroup stratification. Therefore, future studies with larger sample sizes are required in order to validate the results obtained from subgroup analysis. Additionally, univariate analysis demonstrated that tumor diameter was a significant predictor of GC whereas the T stage was not. This may have been due to stage distribution bias in the cohort of the present study. The use of a larger sample size may allow the production of more consistent results.

In conclusion, the present study demonstrated that the $\mathrm{rN}$ score and the Lauren classification were independent prognostic factors for the OS for patients with GC following radical resection. It was determined that the $\mathrm{rN}$ score was more effective at predicting OS for patients with GC following radical resection than $\mathrm{N}$ staging. The data also demonstrated that $\mathrm{rN}$ may be used as an independent predictor of survival in patients with diffuse type GC.

\section{References}

1. Torre LA, Siegel RL, Ward EM and Jemal A: Global cancer incidence and mortality rates and trends-an update. Cancer Epidemiol Biomarkers Prev 25: 16-27, 2016.

2. Chen W, Zheng R, Baade PD, Zhang S, Zeng H, Bray F, Jemal A Yu XQ and He J: Cancer statistics in China, 2015. CA Cancer J Clin 66: 115-132, 2016.

3. Siewert JR, Böttcher K, Stein HJ and Roder JD: Relevant prognostic factors in gastric cancer: Ten-year results of the German Gastric Cancer Study. Ann Surg 228: 449-461, 1998.

4. Edge SB and Compton CC: The American Joint Committee on Cancer: The 7th edition of the AJCC cancer staging manual and the future of TNM. Ann Surg Oncol 17: 1471-1474, 2010.

5. Inoue K, Nakane $Y$, Iiyama $H$, Sato $M$, Kanbara T, Nakai K, Okumura S, Yamamichi K and Hioki K: The superiority of ratio-based lymph node staging in gastric carcinoma. Ann Surg Oncol 9: 27-34, 2002.

6. Nitti D, Marchet A, Olivieri M, Ambrosi A, Mencarelli R, Belluco $\mathrm{C}$ and Lise M: Ratio between metastatic and examined lymph nodes is an independent prognostic factor after D2 resection for gastric cancer: Analysis of a large European monoinstitutional experience. Ann Surg Oncol 10: 1077-1085, 2003.

7. Wang J, Dang P, Raut CP, Pandalai PK, Maduekwe UN, Rattner DW, Lauwers GY and Yoon SS: Comparison of a lymph node ratio-based staging system with the 7th AJCC system for gastric cancer: Analysis of 18,043 patients from the SEER database. Ann Surg 255: 478-485, 2012.

8. Wu XJ, Miao RL, Li ZY, Bu ZD, Zhang LH, Wu AW, Zong XL, Li SX, Shan F, Ji X, et al: Prognostic value of metastatic lymph node ratio as an additional tool to the TNM stage system in gastric cancer. Eur J Surg Oncol 41: 927-933, 2015.

9. Zeng WJ, Hu WQ, Wang LW, Yan SG, Li JD, Zhao HL, Peng CW, Yang GF and Li Y: Lymph node ratio is a better prognosticator than lymph node status for gastric cancer: A retrospective study of 138 cases. Oncol Lett 6: 1693-1700, 2013.

10. Dikken JL, van de Velde CJ, Gönen M, Verheij M, Brennan MF and Coit DG: The New American Joint Committee on Cancer/International Union Against Cancer staging system for adenocarcinoma of the stomach: Increased complexity without clear improvement in predictive accuracy. Ann Surg Oncol 19: 2443-2451, 2012.

11. Zhang BY, Yuan J, Cui ZS, Li ZW, Li XH and Lu YY: Evaluation of the prognostic value of the metastatic lymph node ratio for gastric cancer. Am J Surg 207: 555-565, 2014.
12. Deng J, Zhang R, Wu L, Zhang L, Wang X, Liu Y, Hao X and Liang H: Superiority of the ratio between negative and positive lymph nodes for predicting the prognosis for patients with gastric cancer. Ann Surg Oncol 22: 1258-1266, 2015.

13. Zhao LY, Li CC, Jia LY, Chen XL, Zhang WH, Chen XZ, Yang K, Liu K, Wang YG, Xue L, et al: Superiority of lymph node ratio-based staging system for prognostic prediction in 2575 patients with gastric cancer: Validation analysis in a large single center. Oncotarget 7: 51069-51081, 2016.

14. Espín F, Bianchi A, Llorca S, Feliu J, Palomera E, García O, Remon J and Suñol X: Metastatic lymph node ratio versus number of metastatic lymph nodes as a prognostic factor in gastric cancer. Eur J Surg Oncol 38: 497-502, 2012.

15. Yamashita K, Sakuramoto S, Katada N, Futawatari N, Moriya H, Hirai K, Kikuchi S and Watanabe M: Diffuse type advanced gastric cancer showing dismal prognosis is characterized by deeper invasion and emerging peritoneal cancer cell: The latest comparative study to intestinal advanced gastric cancer. Hepatogastroenterology 56: 276-281, 2009.

16. Zheng H, Takahashi H, Murai Y, Cui Z, Nomoto K, Miwa S, Tsuneyama K and Takano Y: Pathobiological characteristics of intestinal and diffuse-type gastric carcinoma in Japan: An immunostaining study on the tissue microarray. J Clin Pathol 60: 273-277, 2007.

17. Chen YC, Fang WL, Wang RF, Liu CA, Yang MH, Lo SS, Wu CW, Li AF, Shyr YM and Huang KH: Clinicopathological variation of lauren classification in gastric cancer. Pathol Oncol Res 22: 197-202, 2016.

18. Washington K: 7th edition of the AJCC cancer staging manual: Stomach. Ann Surg Oncol 17: 3077-3079, 2010.

19. Lee SR, Kim HO, Son BH, Shin JH and Yoo CH: Prognostic significance of the metastatic lymph node ratio in patients with gastric cancer. World J Surg 36: 1096-1101, 2012.

20. Riediger H, Keck T, Wellner U, zur Hausen A, Adam U, Hopt UT and Makowiec F: The lymph node ratio is the strongest prognostic factor after resection of pancreatic cancer. J Gastrointest Surg 13: 1337-1344, 2009.

21. Zhang J, Lv L, Ye Y, Jiang K, Shen Z and Wang S: Comparison of metastatic lymph node ratio staging system with the 7th AJCC system for colorectal cancer. J Cancer Res Clin Oncol 139: 1947-1953, 2013

22. Wilson M, Rosato EL, Chojnacki KA, Chervoneva I, Kairys JC, Cohn HE, Rosato FE Sr and Berger AC: Prognostic significance of lymph node metastases and ratio in esophageal cancer. J Surg Res 146: 11-15, 2008.

23. Lee SY, Hwang I, Park YS, Gardner J and Ro JY: Metastatic lymph node ratio in advanced gastric carcinoma: A better prognostic factor than number of metastatic lymph nodes? Int J Oncol 36: 1461-1467, 2010.

24. Liu YP, Ma L, Wang SJ, Chen YN, Wu GX, Han M and Wang XL: Prognostic value of lymph node metastases and lymph node ratio in esophageal squamous cell carcinoma. Eur J Surg Oncol 36: $155-159,2010$.

25. Sun Z, Zhu GL, Lu C, Guo PT, Huang BJ, Li K, Xu Y, Li DM, Wang $\mathrm{ZN}$ and $\mathrm{Xu} \mathrm{HM}$ : The impact of N-ratio in minimizing stage migration phenomenon in gastric cancer patients with insufficient number or level of lymph node retrieved: Results from a Chinese mono-institutional study in 2159 patients. Ann Oncol 20: 897-905, 2009.

26. Wong J, Rahman S, Saeed N, Lin HY, Almhanna K, Shridhar R, Hoffe S and Meredith KL: Prognostic impact of lymph node retrieval and ratio in gastric cancer: A U.S. single center experience. J Gastrointest Surg 17: 2059-2066, 2013.

27. Bando E, Yonemura Y, Taniguchi K, Fushida S, Fujimura T and Miwa K: Outcome of ratio of lymph node metastasis in gastric carcinoma. Ann Surg Oncol 9: 775-784, 2002.

28. Dings PJ, Elferink MA, Strobbe LJ and de Wilt JH: The prognostic value of lymph node ratio in node-positive breast cancer: A Dutch nationwide population-based study. Ann Surg Oncol 20: 2607-2614, 2013.

29. Taat CW, van Laschot JJ, Gouma DJ and Obertop H: Role of extended lymph node dissection in the treatment of gastrointestinal tumours: A review of the literature. Scand J Gastroenterol Suppl 212: 109-116, 1995.

30. McCulloch P, Nita ME, Kazi H and Gama-Rodrigues J: Extended versus limited lymph nodes dissection technique for adenocarcinoma of the stomach. Cochrane Database Syst Rev: CD001964, 2004. 
31. Huang J, Hu W, Pang L, Chen J and Yang H: Value of positive lymph node ratio for predicting postoperative distant metastasis and prognosis in esophageal squamous cell carcinoma. Oncol Res Treat 38: 424-428, 2015.

32. Chang YJ, Chung KP, Chen LJ and Chang YJ: Recursive partitioning analysis of lymph node ratio in breast cancer patients. Medicine (Baltimore) 94: e208, 2015.

33. Sun $G$, Xue L, Wang $M$ and Zhao X: Lymph node ratio is a prognostic factor for non-small cell lung cancer. Oncotarget 6: 33912-33918, 2015.

34. Zare Mirzaei A, Abdorrazaghi F, Lotfi M, Kazemi Nejad B and Shayanfar N: Prognostic value of lymph node ratio in comparison to lymph node metastases in stage III colon cancer. Iran J Pathol 10: 127-135, 2015.

35. Zhan HX, Xu JW, Wang L, Zhang GY and Hu SY: Lymph node ratio is an independent prognostic factor for patients after resection of pancreatic cancer. World J Surg Oncol 13: 105, 2015.
36. Flatow V, Warner RR, Overbey J and Divino CM: The prognostic significance of lymph node ratio in carcinoid tumors. Pancreas 45: 342-344, 2016.

37. Choi JK, Park YS, Jung DH, Son SY, Ahn SH, Park DJ and Kim HH: Clinical relevance of the tumor location-modified lauren classification system of gastric cancer. J Gastric Cancer 15: 183-190, 2015.

38. Qiu MZ, Cai MY, Zhang DS, Wang ZQ, Wang DS, Li YH and $\mathrm{Xu}$ RH: Clinicopathological characteristics and prognostic analysis of Lauren classification in gastric adenocarcinoma in China. J Transl Med 11: 58, 2013.

39. Berlth F, Bollschweiler E, Drebber U, Hoelscher AH and Moenig S: Pathohistological classification systems in gastric cancer: Diagnostic relevance and prognostic value. World J Gastroenterol 20: 5679-5684, 2014. 